\title{
Modification of Monodisperse Colloidal Silica by Radical Copolymerizatoin of Cationic Surface Active Vinyl Monomers
}

\author{
By Jung-Min Moon, ${ }^{1}$ Ki-Tae LEE, ${ }^{1}$ Bong-Soo KIM, ${ }^{1}$ \\ Jang-Oo LEE, ${ }^{1, *}$ Toshinori TANAKA, ${ }^{2}$ and Kohji YOSHINAGA ${ }^{2}$
}

Adsorption and polymer modification of colloidal silica by radical copolymerization of surface active monomers, i.e., polymerizable surfactant having a vinyl end group, were investigated. Radical copolymerization of amide ammonium monomer and ammonium-type cross-linker (monomer) using a initiator of 2,2'-azobis(2-amidinopropane) dihydrochloride on colloidal silica successfully led to the formation of monodispersed cross-linked polymer $/ \mathrm{SiO}_{2}$ composites, which is stable in organic solvents. Addition of carboxylic acid monomer to the reaction system of two ammonium monomers gave homogeneously polymer-coated silica composites having carboxyl groups. The composites show $\zeta$-potential of $-36 \mathrm{mV}$ and $0 \mathrm{mV}$ in water and ethanol, respectively.

KEY WORDS: Colloidal Silica / Radical Copolymerization / Surface Active Monomer / Adsorption /

Inorganic-organic composite nanoparticles have attracted much interest, because they possess properties of both inorganic particles and organic molecules, thereby leading to extensive potential applications in various fields of materials science. ${ }^{1-4}$

In order to improve dispersibility in organic phase and compatibility in polymer matrices, polymer modification, including adsorption, coating, or grafting, of inorganic fine particles have been developed. ${ }^{5-8}$

In many cases, the modifications have been carried out by the reaction of surface hydroxyl group on inorganic particles with polymers having isocyanate, alkoxysilane, and chlorosilane groups. ${ }^{9-11}$ We have studied a convenient polymer modification of monodispersed colloidal silica particles using a polymeric coupling agent of trimethoxysilyl terminated maleic anhydride-styrene copolymer. ${ }^{12,13}$ Furthermore, binding of the secondary polymer to the poly(maleic anhydride-costyrene)-modified silica particles resulted in controlling the surface polarity. ${ }^{14}$

However, application of the modification is limited to inorganic colloidal having many hydroxyl groups, such as silica or titania, so it is necessary to exploit a new method to modify colloidal particles having fewer surface hydroxyl groups. Hence, Esumi et al. reported on surface modification of particles using polymerizable surfactants. ${ }^{15-19}$ We also reported the radical polymerization of vinyl monomer and macromer on the particle surface using a cationic azo compound initiator. $^{20,21}$ Furthermore, the adsorption and spontaneous polymerization of head- or tail-type surface active monomers on colloidal particles were investigated. ${ }^{22}$

In this work, we carried out polymer modification of silica nanoparticles by polymerization of amide ammonium-type, cationic vinyl monomers I, II and carboxylic acid monomer III adsorbed on colloidal silica with an AAP initiator, as shown in
Scheme 1. However, attached linear, homopolymers on the surface of silica were separated by washing organic solvents because binding polymer to silica surface is involved by weak electrostatic attraction. ${ }^{20,21}$ So, we report cross-linked polymer modification of monodispersed colloidal silica by radical copolymerization of amide ammonium monomer I and ammonium cross-linker, monomer II (see Scheme 2). In addition, the introduction of carboxyl group functionality in composite by radical copolymerization of monomers I, II and III was also studied.

\section{EXPERIMENTAL}

\section{Materials}

Monodispersed colloidal silica suspended in ethanol, containing $18 \mathrm{wt} \% \mathrm{SiO}_{2}$ of $550 \mathrm{~nm}$ in diameter, was obtained from Catalysts and Chemicals Ind. Co. Ltd., Japan. $N-(N, N, N$,trimethyl ammonium) propylacrylamide chloride (monomer I) was purchased from Wako Pure Chemicals Co., Japan, and obtained as white solid by azeotropic removal of water in ethanol. 2,2'-Azobis(2-amidinopropane) dihydrochloride (AAP, Wako Pure Chemicals Co., Japan) as cationic initiator was recrystallized three times in distilled water. Triethanolamine, diethanolamine, acryloyl choride, carbobenzoxy chloride, succinic anhydride and $p$-nitrophenol were purchased form Wako Pure Chemicals Co., Japan, and used without further purification.

\section{Synthesis of Tri(2-acryloyloxyethyl)ammonium Chloride (Monomer II)}

As shown in Scheme 2, triethanolamine $(0.44 \mathrm{~g})$ was added in the $25 \mathrm{~mL}$ recovery flask and $4 \mathrm{~N}$ hydrochloric acid solution was added dropwise to the flask. After $1 \mathrm{~h}$, aqueous solution was removed by evaporation, and triethanolamine hydrogen

\footnotetext{
${ }^{1}$ Division of Chemical Engineering, Pusan National University, 30 Jangjeon-dong, Geumjeong-gu, Busan 609-735, Republic of Korea

${ }^{2}$ Department of Applied Chemistry, Kyushu Institute of Technology, Sensui, Tobata, Kitakyushu 804-8550, Japan

*To whom correspondence should be addressed (Tel: +82-51-510-2404, Fax: +82-51-513-7720, E-mail: leejo@pusan.ac.kr).
} 


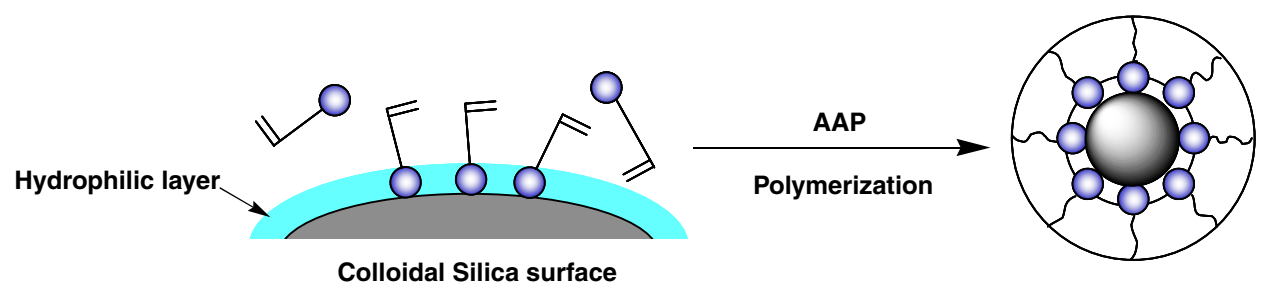<smiles>C=CC(=O)NCCC[N+](C)(C)Cl</smiles>

I<smiles>C=CC(=O)OCCN(CC)CCOC(=O)C=C</smiles>

II<smiles>C=CC(=O)OCCN(CCOC(=O)C=C)C(=O)CC(=O)O</smiles>

III

$=$ Hydrophilic group

Scheme 1. Adsorption and polymerization process of the (cationic) surface active monomer on colloidal silica.
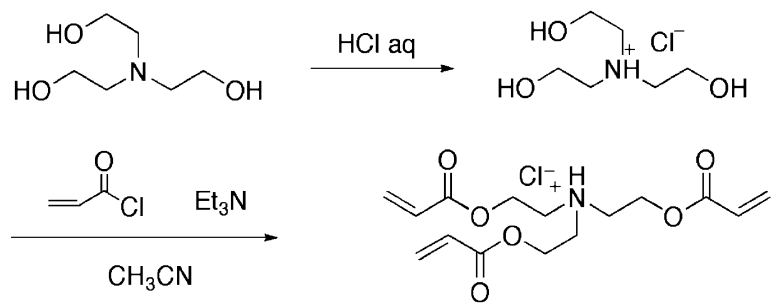

II

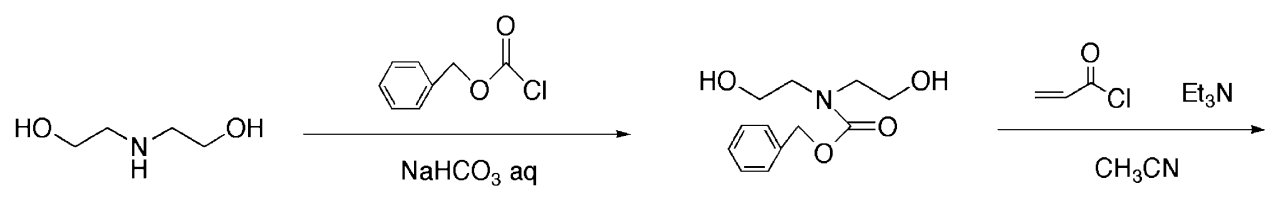

III-a<smiles>C=CC(=O)OCCN(CCOC(=O)C=C)C(=O)OCc1ccccc1</smiles>

III-b

Succinic anhridride/ $\mathrm{Et}_{3} \mathrm{~N}$

DMF<smiles>C=CC(=O)OCCN(CCOC(=O)C=C)C(=O)CCC(=O)O</smiles>

III

Scheme 2. Synthesis of surface active monomers II and III.

chloride salt was obtained as white solid. The obtained salt $(0.60 \mathrm{~g})$ was dissolved in $2.5 \mathrm{~mL}$ triethylamine as $\mathrm{HCl}$ trapper. The mixture was stirred with continuously dropping acryloyl chloride $(0.4 \mathrm{~mL})$ in the $40 \mathrm{~mL}$ dry acetonitrile over a period for $5 \mathrm{~h}$. The solid component was removed by the filtration, and the filtrate was concentrated and extracted with chloroform.
The organic phase was dried overnight over $\mathrm{MgSO}_{4}$, filtered, and evaporated to produce a yellow paste solid, monomer II: yield, $82.1 \%$; ${ }^{1} \mathrm{H}$ NMR $\left(\mathrm{CDCl}_{3}\right), \delta$ (ppm from TMS): 2.92 $\left(6 \mathrm{H}, \stackrel{+}{\mathrm{N} C H} 2_{2}\right), 4.22\left(6 \mathrm{H}, \stackrel{+}{\mathrm{N}} \mathrm{CH}_{2} \mathrm{CH}_{2}-\right), 5.86\left(3 \mathrm{H}, \mathrm{CH}_{2}=\mathrm{CH}\right.$, trans to ethyl acetate group), $6.11\left(3 \mathrm{H}, \mathrm{CH}_{2}=\mathrm{CH}\right), 6.40(3 \mathrm{H}$, $\mathrm{CH}_{2}=\mathrm{CH}$, cis to ethyl acetate group). 


\section{Synthesis of Carboxyl Acrylic Acid Ester Amine (Monomer} III)

Protection of Amino Group. A mixture of $1.0 \mathrm{~g}$ diethanolamine, $1.80 \mathrm{~g}$ benzyloxycarbonyl chloride and $50 \mathrm{~mL}$ sodium hydrogen carbonate solution was stirred at room temperature for $2 \mathrm{~h}$ and then extracted with chloroform. Successive filtration and evaporation gave the resulting product, III-a (see Scheme 2): yield, 92\%; ${ }^{1} \mathrm{H} \mathrm{NMR}\left(\mathrm{CDCl}_{3}\right), \delta$ (ppm from TMS): $3.46\left(4 \mathrm{H}, \mathrm{NCH}_{2}-\right), 3.80\left(4 \mathrm{H}, \mathrm{HOCH}_{2}-\right), 5.13(2 \mathrm{H}$, benzyl), 7.35 (5H, aromatic).

Introduction of Vinyl Group on Terminal Hydroxyl Group of III-a. To the mixture of $2.16 \mathrm{~g}$ III-a and $5 \mathrm{~mL}$ triethylamine, $2.2 \mathrm{~mL}$ acryloyl chloride in dry acetonitrile $(200 \mathrm{~mL})$ was added dropwise with stirring for $5 \mathrm{~h}$. The solid component was removed by the filtration, and the filtrate was concentrated and extracted with chloroform. The organic phase was dried over $\mathrm{MgSO}_{4}$ overnight, filtered, and evaporated to obtain the resulting product, III-b (see Scheme 2): yield, 88\%; ${ }^{1} \mathrm{H}$ NMR $\left(\mathrm{CDCl}_{3}\right), \delta$ (ppm from TMS): $3.64\left(4 \mathrm{H}, \mathrm{CONCH}_{2}-\right), 4.30(4 \mathrm{H}$, $\left.\mathrm{COOCH}_{2}-\right), 5.14\left(2 \mathrm{H}\right.$, benzyl), $5.84\left(2 \mathrm{H}, \mathrm{CH}_{2}=\mathrm{CH}\right.$, trans to ethyl acetate group), $6.09\left(2 \mathrm{H}, \mathrm{CH}_{2}=\mathrm{CH}\right), 6.40\left(3 \mathrm{H}, \mathrm{CH}_{2}=\mathrm{CH}\right.$, cis to ethyl acetate group), 7.35 (5H, aromatic).

Introduction of Carboxyl Group of III-b by Ring Opening of Succinic Anhydride. A mixture of $1.02 \mathrm{~g}$ of III-b and $10 \mathrm{~mL}$ of $25 \%$ hydrobromic acid in pure acetic acid (1/9 vol) was stirred for $30 \mathrm{~min}$ to remove the protecting group. Precipitation with ether, successive filtration and drying under reduced pressure gave the bromic acid salt. And then a solution of $0.82 \mathrm{~g}$ bromic acid salt, $0.30 \mathrm{~g}$ succinic anhydride, $1.25 \mathrm{~mL}$ triethylamine and $40 \mathrm{~mL}$ DMF was stirred at room temperature for $2 \mathrm{~h}$ and extracted with chloroform. The extract was dried over $\mathrm{MgSO}_{4}$ overnight, filtered, and evaporated to produce a resulting final product, monomer III: yield, $82 \% ;{ }^{1} \mathrm{H} \mathrm{NMR}\left(\mathrm{CDCl}_{3}\right), \delta$ (ppm from TMS): $2.66\left(2 \mathrm{H}, \mathrm{HOOCCH}_{2} \mathrm{CH}_{2}-\right), 2.73(2 \mathrm{H}$, $\left.\mathrm{HOOCCH}_{2}-\right), 3.69\left(4 \mathrm{H}, \mathrm{CONCH}_{2}-\right), 4.33\left(4 \mathrm{H}, \mathrm{COOCH}_{2}-\right), 5.86$ $\left(2 \mathrm{H}, \mathrm{CH}_{2}=\mathrm{CH}\right.$, trans to ethyl acetate group), $6.11(2 \mathrm{H}$, $\left.\mathrm{CH}_{2}=\mathrm{CH}\right), 6.40\left(2 \mathrm{H}, \mathrm{CH}_{2}=\mathrm{CH}\right.$, cis to ethyl acetate group).

\section{Adsorption of Surface Active Monomers on Colloidal Silica}

To the suspension of colloidal silica in $7.5 \mathrm{~mL} \mathrm{THF} / \mathrm{H}_{2} \mathrm{O}$ (9/1 vol) containing $0.225 \mathrm{~g} \mathrm{SiO}_{2}$, each monomer was added and the mixture was stirred at room temperature for $2 \mathrm{~h}$ under nitrogen atmosphere. The adsorption amount of the monomer on silica was estimated form the concentration in the supernatant, which was separated by centrifugation, employing the values for absorption (or extinction) coefficients: $\varepsilon=98.04$ at $272 \mathrm{~nm}$ for monomer I, $\varepsilon=1268.23$ at $328 \mathrm{~nm}$ for monomer II, and $\varepsilon=555$ at $328 \mathrm{~nm}$ for monomer III.

\section{Polymerization on Colloidal Silica to Give Composites 1 and 2}

A typical run was as follows. Monomers I and II in the mole ratio of $1 / 1$ were added to the suspension of colloidal silica in $15 \mathrm{~mL} \mathrm{THF} / \mathrm{H}_{2} \mathrm{O}$ (9/1 vol) solution, containing $0.45 \mathrm{~g} \mathrm{SiO}_{2}$, followed by the addition of AAP initiator of $10 \mathrm{~mol} \%$ of monomers. The mixture was gently stirred at $65^{\circ} \mathrm{C}$ for $4 \mathrm{~h}$ in a nitrogen atmosphere. Centrifugal washing (; washing by centrifugation) from the ethanol five times and drying under vacuum gave the silica composite 1 . In addition, the silica composite 2 was prepared by the copolymerization of monomers I and II with fixed mole ratio of $2 / 1$ and monomer III of varying content, in the manner similar to that described above.

Determination of Surface Carboxyl Group on Composite 2

A mixture of $20 \mathrm{mg}$ silica composite $2,15 \mathrm{mg} N, N^{\prime}$ dicyclohexylcarbodiimide (DCC) and $5 \mathrm{~mL}$ dry chloroform was stirred for $2 \mathrm{~h}$ at $0{ }^{\circ} \mathrm{C}$. And then $10 \mathrm{mg} p$-nitrophenol was added to the solution and stirred for $12 \mathrm{~h}$ at room temperature. The resulting particles were washed with methanol five times in order to remove any unreacted $p$-nitrophenol by a centrifugation and dried under vacuum. To $4 \mathrm{~mL}$ of $4 \%$ ammonium hydroxide solution, the resulting particles $(10 \mathrm{mg})$ were added and stirred for $12 \mathrm{~h}$ in order to hydrolyze. The surface carboxyl group was measured by the concentration of $p$-nitrophenol ( $\varepsilon=18000$ at $400 \mathrm{~nm}$ ) in the supernatant, which was obtained by a centrifugation.

\section{Measurement}

The synthesized monomers and composites were characterized by ${ }^{1} \mathrm{H}$ NMR and solid state HR-MAS ${ }^{1} \mathrm{H}$ NMR spectroscopy on a JEOL JNM-A500 and a Bruker AVANCE400 using a $7 \mathrm{~mm}$ probe instrument, respectively. Scanning electron micrographs (SEM) were taken by a JEOL JSM6320F. Measurement of the particle size and distribution in ethanol were measured by a dynamic light scattering (DLS) method on an Ohtsuka DLS-700S. $\zeta$-potental of composite particles suspended in water and ethanol was measured by a light scattering electrophoresis on an Ohtsuka ELS-800. Thermo-gravimetric analyses (TGA) studies on the composites were performed on a Shimadzu TGA-50. Ultraviolet spectra were recorded by spectrophotometric absorption method on a JASCO V-520S.

\section{RESULTS AND DISCUSSION}

Since colloidal silica generally has a negative charge under neutral condition, ammonium monomer is expected to be adsorbed effectively on the silica by the electrostatic force as to give the Langmuir-type adsorption isotherm. In fact, the adsorption of the present surface active vinyl monomers on silica will be primarily affected by the electron density on nitrogen atom and the bulkiness around the nitrogen atom rather than the interaction of vinyl groups. Actually, however, the primary effect may be about the same for three types of monomers studied. Hence, we will proceed the difference in adsorption behavior among three monomers from the viewpoint of the interaction of vinyl groups concerned. The adsorption behavior of surface active vinyl monomers I, II, and III on silica surface was separately examined in THF $/ \mathrm{H}_{2} \mathrm{O}$ $(9 / 1 \mathrm{vol})$ on the same experimental conditions. As shown in Figure 1, the adsorption behavior of all the three monomers on 


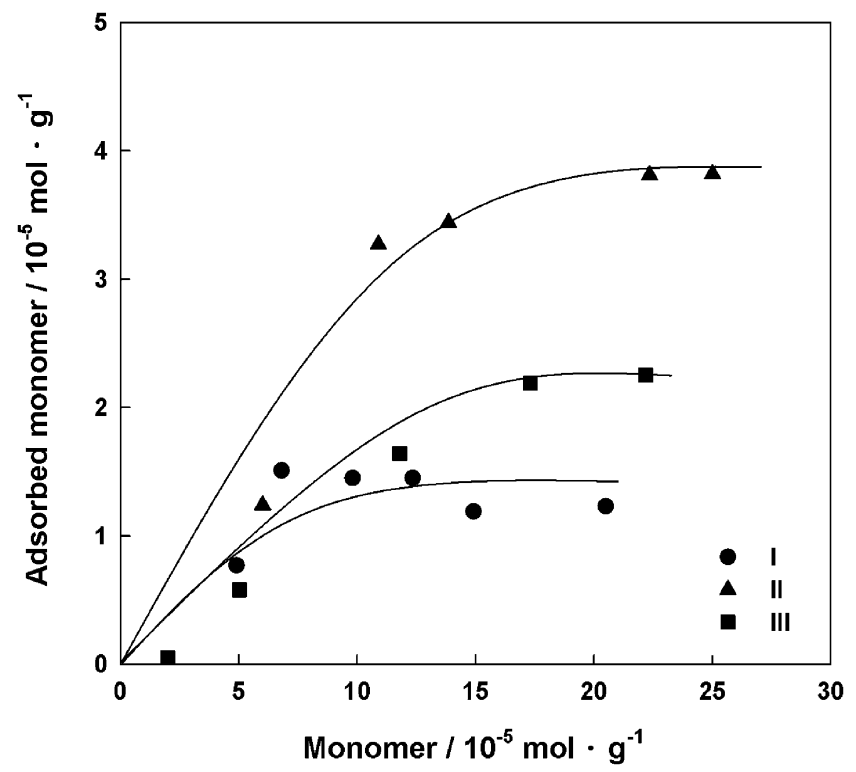

Figure 1. Adsorption isotherms of monomers I, II and III on colloidal silica.

colloidal silica gave the Langmuir-type adsorption isotherms, as expected. Each amount of adsorbed monomer increases gradually at low monomer concentrations, and then becomes nearly constant with further increase of the monomer concentration over $20 \times 10^{-5} \mathrm{~mol} \cdot \mathrm{g}^{-1}$. The monomer II (called the ammonium cross-linker) gave the highest adsorption on silica, which is probably due to presence of many vinyl groups, thereby forming aggregation through $\pi-\pi$ interactions between vinyl groups of the adsorbed monomer. By contrast, the amide ammonium monomer I will be adsorbed via both electrostatic interaction of cationic region and hydrogen bonding with silanol groups on colloidal silica, and hence the adsorption area per monomer is expected to be larger than others. Therefore, the amount of adsorbed monomer I was considerably smaller compared with monomers II and III. The monomer III with undissociated carboxylic groups will be adsorbed via hydrogen bonding between the carboxyl and the silanol groups on silica surface. Comparison of monomers II and III suggests that electrostatic interaction is more effective for adsorption than hydrogen bonding between the surface active vinyl monomer and silica. As judged from the adsorption isotherms given in Figure 1, it is expected to copolymerize monomers I and II or monomers I, II and III on colloidal silica.

Ammonium type vinyl monomers will be adsorbed on the hydrophilic colloidal particle surface. Copolymerization of monomers I and II with an AAP initiator on colloidal silica was carried out at different monomer ratios in $\mathrm{THF} / \mathrm{H}_{2} \mathrm{O}(9 / 1 \mathrm{vol})$. The resulting silica composite 1 encapsulated by I/II crosslinked copolymer was washed 5 times with ethanol by centrifugation and dried under vacuum. A typical HR-MAS ${ }^{1} \mathrm{H}$ NMR spectrum of composite 1 is shown in Figure 2(a). From the spectrum, the occurrence of the copolymerization on the silica surface was confirmed by the existence of proton signal at $4.23 \mathrm{ppm}$, assignable to protons of $\alpha$ position of ester group, and at $2.95 \mathrm{ppm}$, assignable to protons of $\alpha$ position
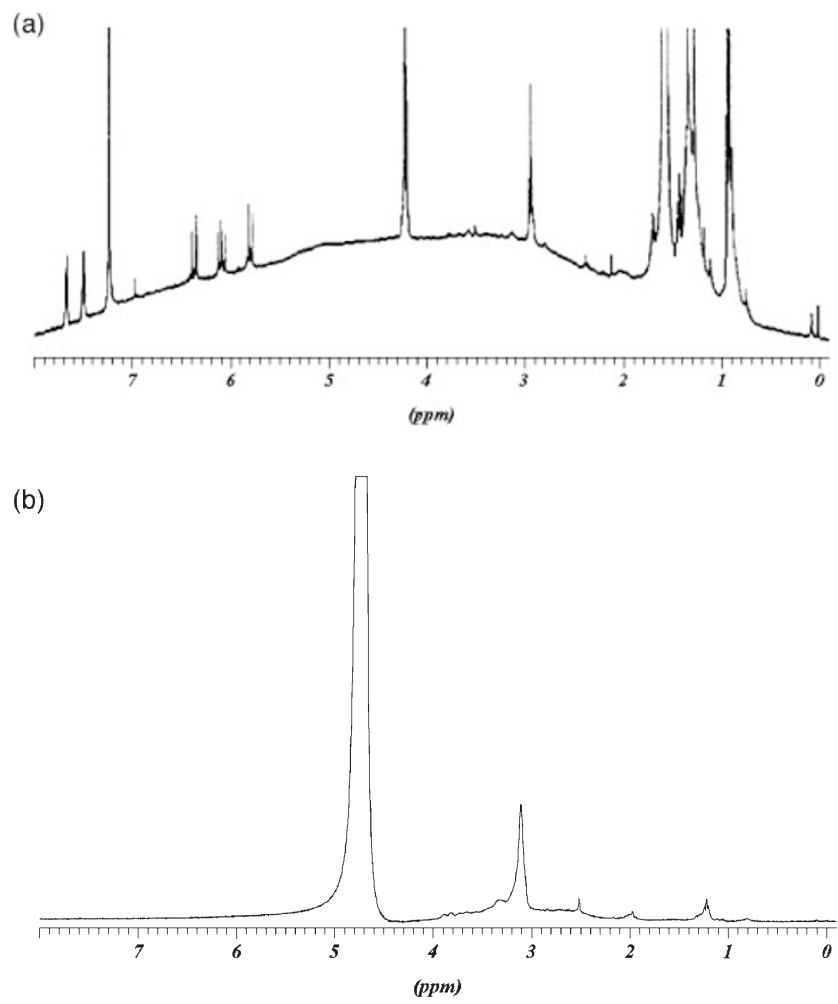

Figure 2. HR-MAS ${ }^{1} \mathrm{H}$ NMR spectra of (a) composite 1 and (b) composite 2 .

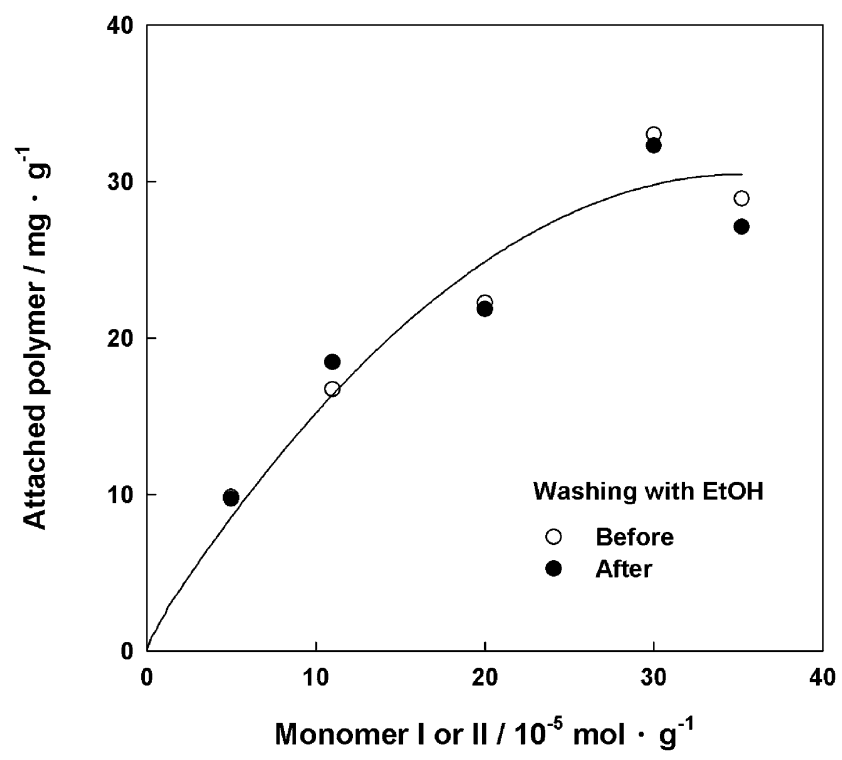

Figure 3. Copolymerization of monomers I and II on colloidal silica at $65^{\circ} \mathrm{C}$ in $\mathrm{THF} / \mathrm{H}_{2} \mathrm{O}(9 / 1 \mathrm{vol})$. Solvent, $15 \mathrm{~mL} ; \mathrm{SiO}_{2}, 0.45 \mathrm{~g}$; Mole ratio, $\mathrm{I} / \mathrm{II}=1 / 1$.

of amide group of monomers. In addition, it was recognized that all vinyl groups of monomer II did not participate in copolymerization, as inferred from the existence of proton signals assignable to vinyl groups. Figure 3 shows the attached polymer and stability of silica composite in organic solvents. Open circle and closed circle symbols denote silica composite 

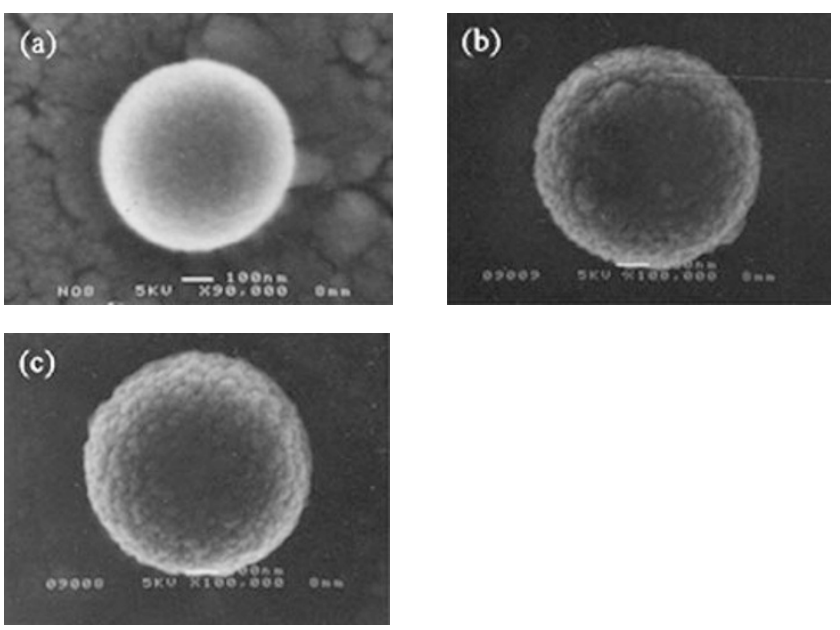

Figure 4. SEM images of (a) original silica, (b) composite 1 and (c) composite 2. Scale bars on the bottom of photographs represent $100 \mathrm{~nm}$.

before and after washing with ethanol, respectively. Attached polymer on the surface of silica was increased with increasing monomer content, but became constant around monomer concentration of $30 \times 10^{-5} \mathrm{~mol} \cdot \mathrm{g}^{-1}$. In addition, significant loss of attached polymer of silica by washing with ethanol was not observed. This result may indicate that silica particle was coated with cross-linked polymer in three dimensions and it is well supported with SEM image (Figure 4). Also, dynamic light scattering (DLS) experiment showed that the particles were distributed nearly in the same size range as that of the unmodified colloidal silica.

To introduce the acidic functional group on the surface of silica, carboxylic acid monomer III was added to the reaction system of two ammonium monomers and copolymerization was carried out. The monomer III will interact with hydrophilic surface of silica via the hydrogen bond, so is considered to be concentrated on the colloidal silica surface and copolymerized with monomers I and II in the presence of AAP initiator in $\mathrm{THF} / \mathrm{H}_{2} \mathrm{O}(9 / 1 \mathrm{vol})$. Table I shows the reaction condition of copolymerization to give composite 2 . The amounts of attached polymer and carboxyl group on the surface of composite were increased with increasing carboxyl acid monomer content, and it is possible to obtain composite 2 having the maximum value in the carboxyl group of $7 \mu \mathrm{mol} / \mathrm{g}$. From the ${ }^{1} \mathrm{H}$ NMR spectrum of composite 2 (Figure 2(b)), it is recognized that copolymerization on the silica surface occurred from the existence of proton signals corresponding to each monomer and disappearance of proton signals assignable to protons of vinyl groups. The silica composite 2 as well as composite 1 was homogeneously coated with the I/II/III cross-linked copolymer, having many spots on the surface, while original silica exhibits more smooth surface than those of the composites, as shown in Figure 4. It suggests that copolymerization of surface active vinyl monomers on colloidal silica occurred by the 'water pool mechanism' associated with spontaneous polymerization of polymerizable surfactant. ${ }^{22}$ As estimated from the DLS experiment, the thickness of polymer
Table I. Amounts of attached polymer and carboxyl group on composite $2^{\text {a) }}$

\begin{tabular}{ccccc}
\hline \multicolumn{3}{c}{ Monomer concentration } & A.P. & COOH \\
I $\left(10^{-5} \mathrm{~mol} \cdot \mathrm{g}^{-1}\right)$ & II $\left(10^{-5} \mathrm{~mol} \cdot \mathrm{g}^{-1}\right)$ & III $\left(10^{-5} \mathrm{~mol} \cdot \mathrm{g}^{1}\right)$ & $\begin{array}{c}\left.\mathrm{COg} \cdot \mathrm{g}^{-1}\right) \\
\left(\mu \mathrm{mol} \cdot \mathrm{g}^{-1}\right)\end{array}$ \\
\hline 4.75 & 2.25 & - & 4.1 & - \\
& 10.12 & 10.2 & 0.72 \\
& 19.84 & 17.3 & 2.44 \\
& 30.87 & 18.5 & 5.49 \\
& 50.10 & 32.7 & 7.00 \\
\hline
\end{tabular}

a) Radical colymerization of monomers I + II + III on colloidal silica in $\mathrm{THF} / \mathrm{H}_{2} \mathrm{O}$ initiated by AAP at $65^{\circ} \mathrm{C}$ for $4 \mathrm{~h}$. b) A.P. = Attached polymer. Measured by weight decrease from $100^{\circ} \mathrm{C}$ to $800^{\circ} \mathrm{C}$ on TGA curves.

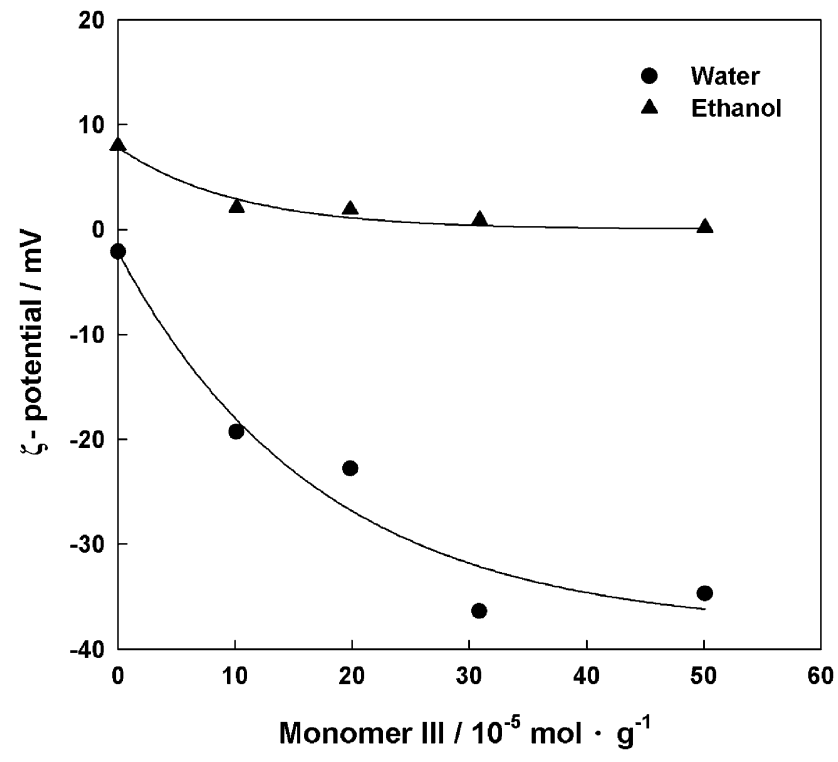

Figure 5. $\zeta$-potential of the composite 2 with monomer III addition in the copolymerization.

on composite was about $6.88 \mathrm{~nm}$. Hence, the increase of particle size by copolymerization seemed to be quite small, reflecting almost the retention of the particle size.

It is also considered that the present polymer modification changed surface properties of colloidal silica. In Figure 5, changes of $\zeta$-potential values of composite 2 with monomer III content in water and ethanol are shown, respectively. The composite particles gave the $\zeta$-potential of $-36 \mathrm{mV}$ and $0 \mathrm{mV}$ in water and ethanol, respectively. The $\zeta$-potential significantly increased negatively with carboxylic acid monomer (III) content in water. The large negative potential of composite particle in water is due to dissociation by carboxyl groups. In ethanol, however, the $\zeta$-potential only slightly decreased with monomer III content probably due to much less dissociation of carboxyl groups than in water. Therefore, it is possible to control $\zeta$-potential of silica surface by the present system.

\section{CONCLUSIONS}

Radical copolymerization of ammonium type vinyl monomers I and II, adsorbed on colloidal silica particles by the electrostatic attraction, gave silica composite 1 coated with I/II 
copolymer coated in three dimensions, almost retaining the particle size. The addition of carboxylic acid monomer (III) to the reaction system of two ammonium monomers gave silica composite 2 having the maximum carboxyl group of $7 \mu \mathrm{mol} / \mathrm{g}$. The composite 2 particles were dispersed by electrostatic repulsion due to highly negative $\zeta$-potential in water and by the steric repulsion of grafted polymer chains in ethanol.

Acknowledgment. This work was supported for two years by Pusan National University Research Grant.

Received: October 30, 2008

Accepted: November 21, 2008

Published: January 15, 2009

\section{REFERENCES}

1. H. S. Nalwa, "Handbook of Nanostructured Materials and Nanotechnology," Academic Press, San Diego, 2000.

2. F. Caruso, Adv. Mater., 13, 11 (2001).

3. L. L. Beecroft and C. K. Ober, Chem. Matter., 9, 1302 (1997).

4. T. Von Werne and T. E. Pattern, J. Am. Chem. Soc., 121, 7409 (1999).

5. R. Kroker, H. Schneider, and K. Hamann, Prog. Org. Coat., 1, 23 (1972).

6. R. Laible and K. Hamann, Adv. Colloid Interface Sci., 13, 65 (1980).
7. N. Tsubokawa, A. Kogure, Y. Sone, and M. Shimomura, Polym. J., 21, 475 (1989).

8. N. Tsubokawa, A. Kogure, and Y. Sone, J. Polym. Sci., Part A: Polym. Chem., 28, 1923 (1990).

9. N. Tsubokawa, K. Maruyama, Y. Sone, and M. Shimomura, Colloid Polym. Sci., 267, 511 (1989).

10. K. P. Krenkler, R. Laible, and K. Hamann, Angew. Macromol. Chem., 53, 101 (1976).

11. Y. Chujo, E. Ihara, and T. Saegusa, Macromolecules, 22, 2040 (1989).

12. K. Yoshinaga and K. Nakanishi, Compos. Interfaces, 2, 95 (1994).

13. K. Yoshinaga, K. Nakanishi, Y. Hidaka, and H. Karakawa, Compos. Interfaces, 3, 231 (1995).

14. K. Yoshinaga and M. Teramoto, Bull. Chem. Soc. Jpn., 69, 2667 (1996).

15. J. H. Harwell, J. C. Hoskins, R. S. Schechter, and W. H. Wade, Langmuir, 1, 251 (1985).

16. S. Manne, J. P. Cleveland, H. E. Granb, G. D. Stucky, and P. K. Hansma, Langmuir, 10, 4409 (1994).

17. J. Wu, J. H. Harwell, and E. A. O'Rear, Langmuir, 3, 531 (1987).

18. K. Esumi, N. Watanabe, and K. Meguro, Langmuir, 5, 1420 (1989).

19. K. Esumi, N. Watanabe, and K. Meguro, Langmuir, 7, 1775 (1991).

20. K. Yoshinaga, T. Yokoyama, Y. Sugawa, H. Karakawa, N. Enomoto, H. Nishida, and M. Komatsu, Polym. Bull., 28, 663 (1992).

21. K. Yoshinaga, T. Yokoyama, and T. Kito, Polym. Adv. Technol., 4, 38 (1993).

22. K. Yoshinaga, F. Kakashima, and T. Nishi, Colloid. Polym. Sci., 277, 136 (1999). 